\title{
O uso de matrizes de polipropileno e moldagens preliminares em alginato - técnica simplificada
}

\author{
Ézio Teseo Mainieri*** \\ Luiz Fernando Walber** \\ Myriam K. Tzovenos*
}

\begin{abstract}
RESUMO
Os autores descrevem a confecçāo de pontes fixas provisórias a partir do uso preferencial de matrizes de polipropileno ou moldagens preliminares em alginato. É comentada a relação entre o uso de provisórios bem ajustados e o estabelecimento da saúde periodontal
\end{abstract}

\section{SUMMARY}

The authors describe the technique of temporary bridges and splints construction with the use of either polypropilene matrix or alginate impressions.

\section{UNITERMOS}

Restauração dental temporária, Prótese periodontal, Splints.

\section{Introdução}

A temporizaçăo adequada é um pré requisito para o sucesso em tratamentos protético periodontais. É necessário estabelecer e manter a função normal e o preciso relacionamento entre os dentes para conseguir proteçăo à polpa dental, boa estética e manutenção da saúde tecidual. Através da construção de bons splints ou pontes fixas provisórias podemos criar uma oclusão funcional, distribuir o stress verticalmente sobre os dentes e evitar o trauma oclusal.

Após a terapia periodontal estes provisórios podem ser reembasados, a oclusão ideal ao caso é estabelecida e depois pode ser mantida na prótese definitiva. $O$ uso de bons provisórios, associado às raspagens, curetagem e cuidados caseiros frequentemente levará a um tratamento periodontal mais rápido que o previsto inicialmente. Na reavaliação periodontal também pode ser melhorado o prognóstico inicial de certos dentes.
Os materiais mais usados na confecção de provisórios são as resinas acrílicas autopolimerizáveis. Sua vida útil como elementos provisórios é de aproximadamente 6 meses. Elas sáo menos resistentes do que o acrílico termopolimerizável e após este período năo é possível a manutenção das relaçōes oclusais obtidas devido ao desgaste. Ocorre também a descoloração do material. Devido a isso, splints de acrílico termopolimerizável são ainda necessários em muitos casos.

\section{Temporização de pontes com vários elementos}

Quando trabalhamos com pontes fixas ou com grandes splints temporários, podemos optar entre duas maneiras de executá-los. A técnica de primeira escolha, por ser mais precisa e sofisticada é a construção de provisórios a partir de matrizes de polipropileno obtidas com o uso do Plastificador a Vácuo (Bio-Art), como segunda opção podemos utilizar uma impressão em alginato da arcada em questão. A matriz de polipropileno e a moldagem em alginato registram a forma e a posição dos dentes que serăo preparados. A região mais crítica junto aos bordos cervicais deve ser aliviada com um bisturi afiado, no caso da moldagem com alginato e devemos aliviar as regiōes cervicais dos dentes no modelo com cera antes de processarmos a matriz de polipropileno a vácuo.

Desta forma, ao colocarmos a mistura de acrílico esta zona ficará mais espessa, tornando o acabamento mais fácil e preciso.

Para preparar a matriz de polipropileno precisamos de um modelo de estudo. Neste modelo esculpiremos em cera o pôntico e espessaremos a região cervical dos pilares, permitindo depois um acabamento mais apurado. Sugerimos o uso do disco de $0,5 \mathrm{~mm}$ que acompanha o aparelho

\footnotetext{
** Professor Adjunto

** Professor Auxiliar de Ensino

* Especialista em Prótese Dental
}

\begin{tabular}{|c|l|l|l|l|l|l|}
\hline R. Fac. Odontol. & Porto Alegre & V. 33 & N.2 & p.28-31 & DEZEMBRO & 1992 \\
\hline
\end{tabular}


para este fim. A matriz de polipropileno é preenchida com uma mistura espessa de acrílico autopolimerizável e colocada em boca. A primeira remoçăo é feita aproximadamente 4 minutos após a inserção, tempo suficiente para o acrílico iniciar o processo de polimerização sobre o dente.

Ao removermos a moldagem ou matriz da boca ocorre com frequência do acrílico permanecer na matriz. Neste caso devemos remover o acrílico do molde com delicadeza e posicioná-lo sobre os dentes. 0 arco oposto é então colocado em oclusão. Com uma espátula Hollemback removemos o acrílico que penetrou ns ameias e adaptamos meIhor aos bordos. Os excessos mais grosseiros devem ser removidos com tesouras.

O acrílico em fase de polimerização deve ser removido e reposicionado várias vezes em boca, para que se dissipe o calor da polimerização sem que ocorram injúrias a polpa e tecidos moles. Outro motivo para várias remoçōes e reposicionamentos do acrílico em fase de polimerização é o fato deste material contrair-se muito. Se ele polimerizar sem ser removido de sua posição original, pode ficar preso por contração ao preparo ou por presença de excessos nas ameias, saindo só se for cortado.

Esta técnica é uma opção de trabaIho a mais, apesar de não ser a mais adequada, em vista da possibilidade de causar danos a polpa e tecidos moles, pelo contato direto. A aplicação correta é sem dúvida o uso da técnica com a matriz de polipropileno, descrita a seguir.

É interessante pincelar um isolante sobre os dentes antes de iniciar a confecção dos provisórios. Podem ser usados óleo mineral ou vaselina.

Podemos economizar tempo junto ao paciente construindo splints em nosso próprio laboratório. Uma assistente dental pode ser treinada. Em um bom modelo de estudo preparamos uma matriz de polipropileno com $0,5 \mathrm{~mm}$ de espessura (fig. 1).

Após o preparo dos dentes tomamos uma impressão com alginato e a

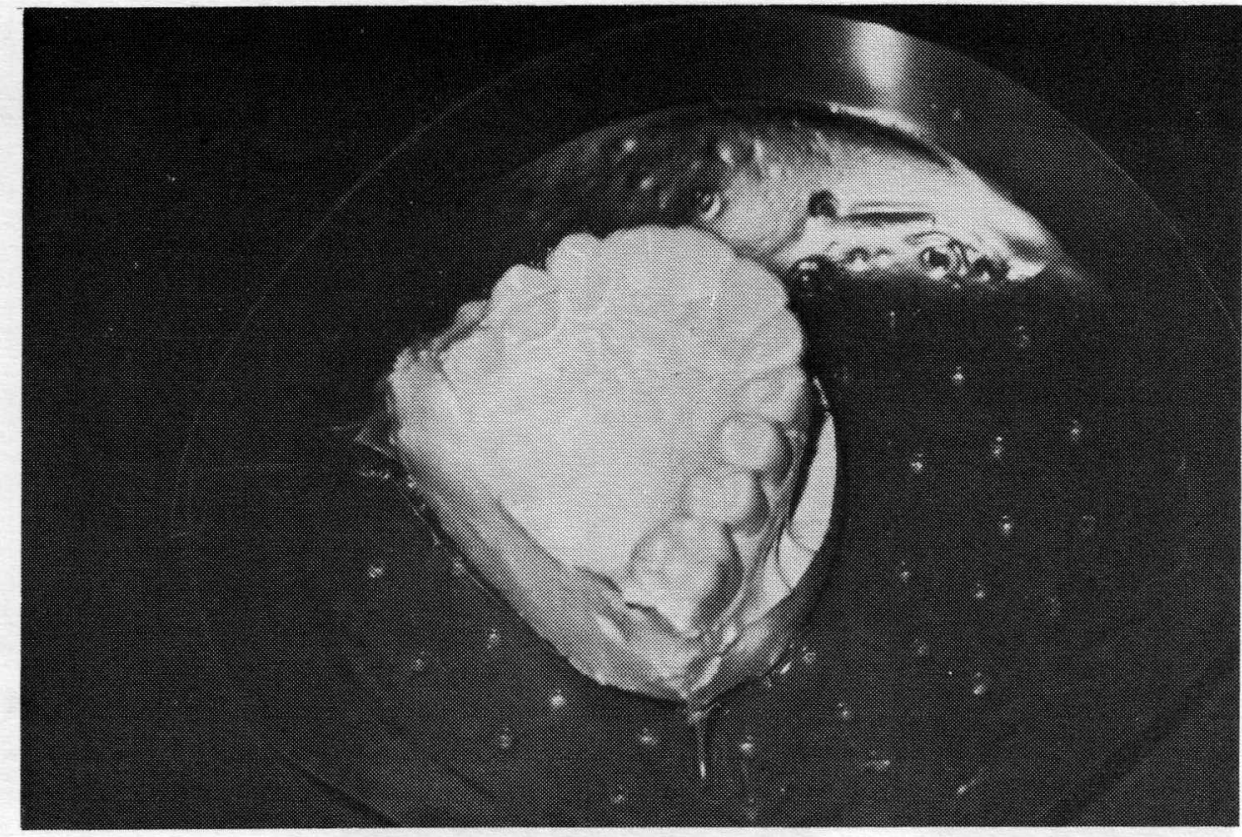

Fig. 1: Matriz de polipropileno adaptada sobre o modelo, após a plastificaçāo

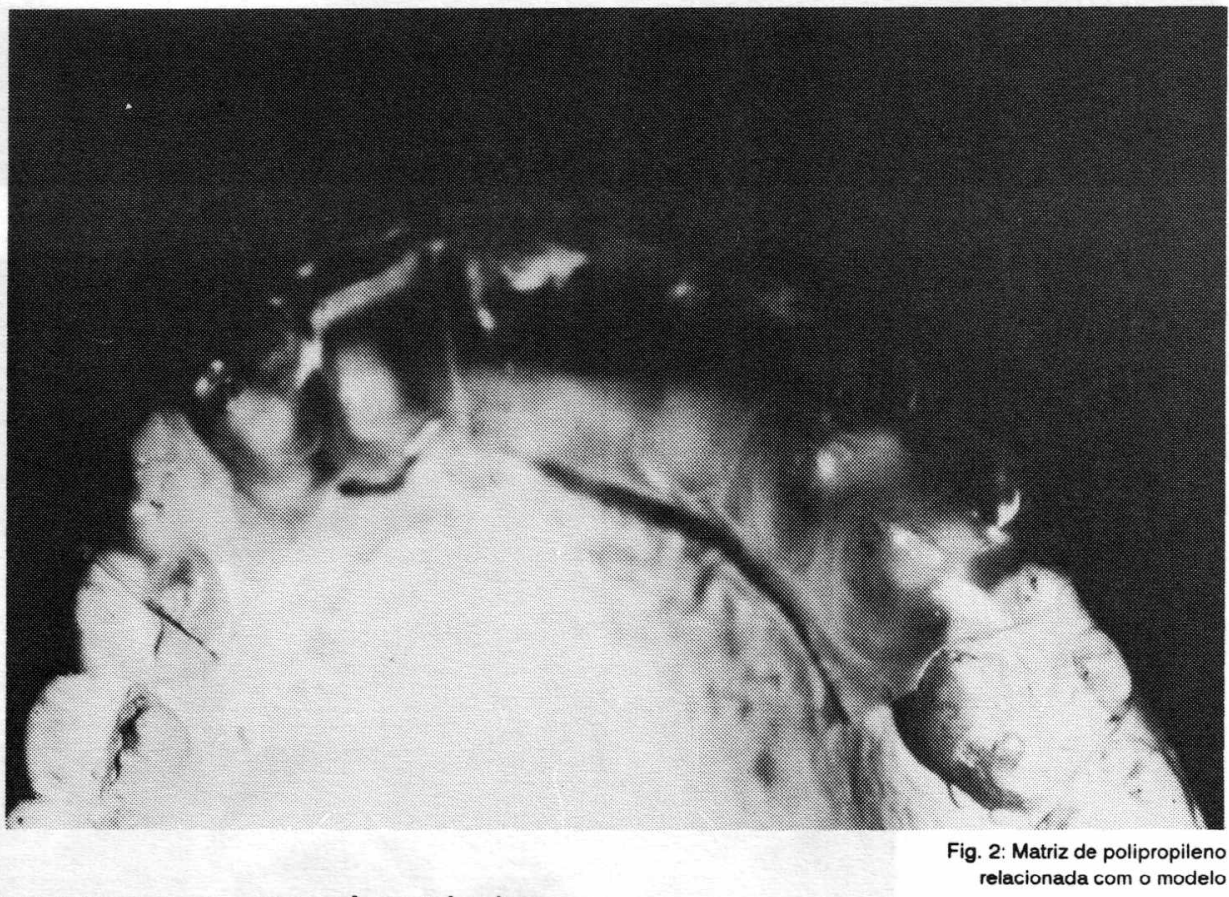

vazamos com gesso. A matriz de polipropileno preparada previamente é provada sobre o modelo obtido dos dentes recém preparados (fig. 2). Ela tomará contato com alguns tecidos moles (no modelo) que funcionarão como stops. O modelo dos dentes preparados deve ser pincelado com um isolante (Al-Cote/Cel-Lac). Colocamos entăo uma mistura de acrílico na tonalidade desejada na matriz, a assentamos sobre o modelo dos dentes preparados (fig. 3).
Viramos o modelo ao contrário e amarramos à matriz com uma borracha forte. Enquanto o acrílico polimeriza, deve ser mantido em água morna em um recipiente pressurizado. Quando o bloco de acrílico estiver polimerizado, deverá ser internamente aliviado, proporcionando alojamento adequado aos dentes preparados. Devem ser criados contornos dentários normais, ameias adequadas e a oclusão obtida deve ser veri-

\section{R. Fac. Odontol.}




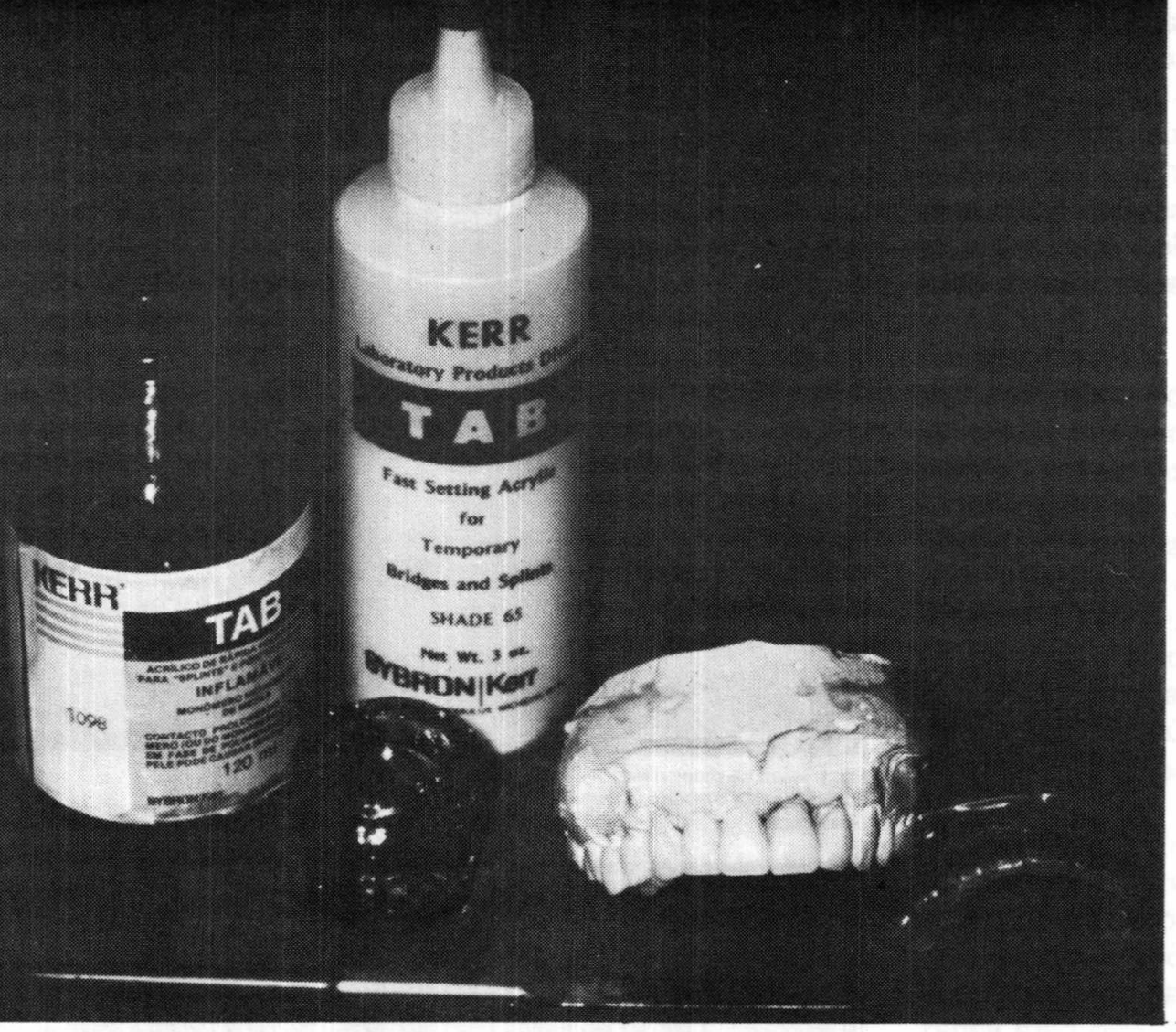

Fig. 3: Acrílico (monômero + polímero) férula provisória colocada no modelo

Fig. 4: Férula provisória finalizada

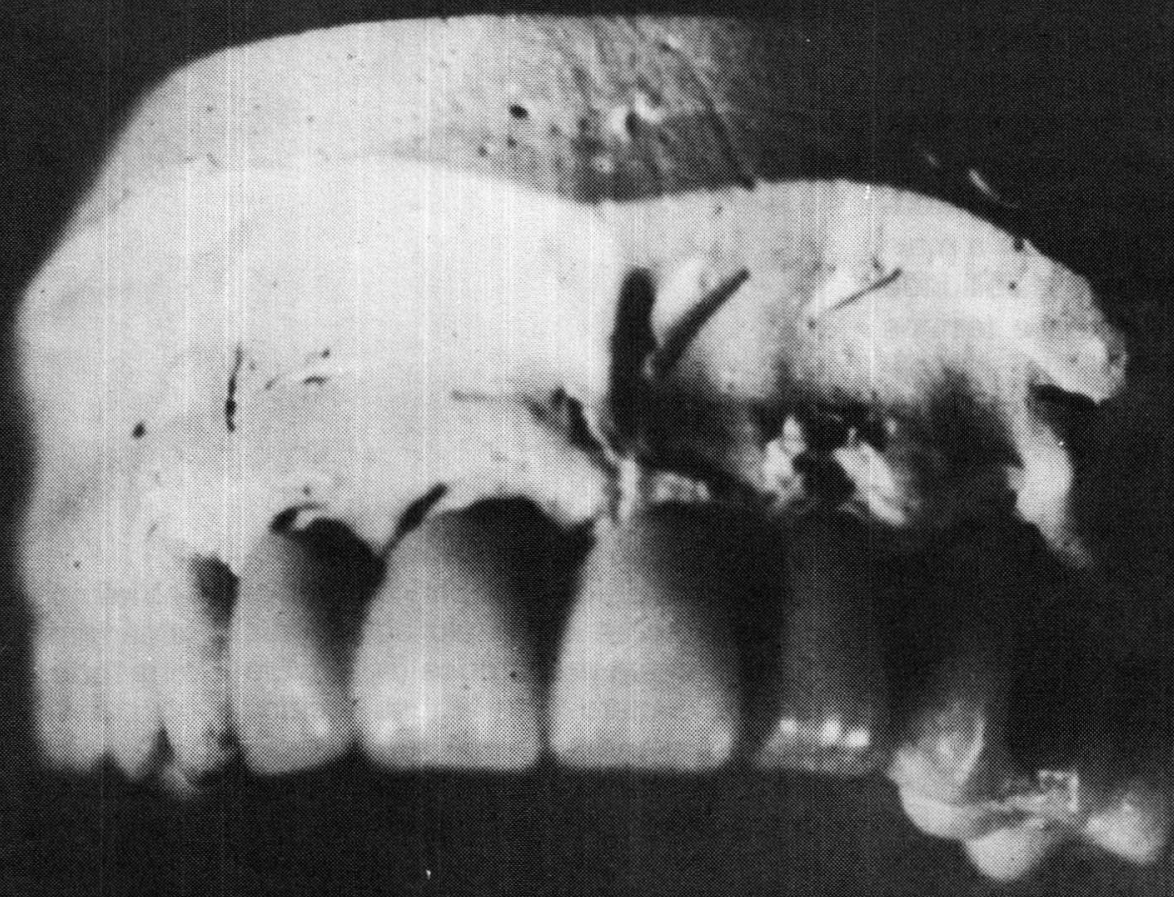


ficada. Estas condições serão alcançadas tanto pela redução do excesso de acrílico como pela sua adição ao splint pela técnica do pincel. Um splint feito desta maneira terá menos porosidade por bolhas de ar e será mais durável em boca quando comparados com a técnica anterior (fig. 4).

Ao darmos acabamento em um provisório, primeiro delineamos as margens com lápis, recortamos e depois preparamos as ameias. Quando os contornos estiverem prontos alisaremos as superfícies com uma lentilha de borracha. O acabamento das oclusais pode ser feito com uma broca 702 em peça de mão. O polimento pode ser feito com o uso de discos de feltro ou escovas em forma de disco (alcançam as ameias) e vaselina sólida. Frequentemente o splint fica tão justo que necessita algum alívio interno com uma broca esférica número 10 para dar lugar ao cimento.

Alguns profissionais encontrarão no exercício da construção de pontes provisórias um ótimo caminho para aprender e desenvolver a sensibilidade para a anatomia dentária. Todos os procedimentos já descritos podem ser adotados para a construçăo de unitários e onlays.

A cimentaçăo das coroas e pontes provisórias deve ser realizada com produtos que não afetem (ou afetem minimamente) os procedimentos de reembasamento ou conserto do acrílico. Os cimentos temporários contém óleos tais como o eugenol que afetem a presa do acrílico autopolimerizável.

O Temp-Bond sem eugenol da Kerr é o cimento provisório de maior sucesso e não tem maiores efeitos sobre o acrílico. $O$ eugenol dos cimentos temporários após um período amolecem o interior das coroas. Dependendo do tempo que ficarăo em boca os provisórios, poderemos usar outros cimentos, como os policarboxilatos ou o fosfato de zinco, que darão mais retenção e não afetarão consertos ou reembasamentos.

Muito pode ser feito com uma restauração temporária. Se o paciente tem diminuição da dimensão vertical e você deseja determinar uma certa abertura, faça-o simplesmente adicionando acrílico de rápida polimerização nas superfícies oclusais, mantendo o paciente em uma determinada posição de oclusão até a polimerização do material. Depois refazemos a anatomia oclusal. O paciente usará esta ponte por um certo período para determinar se é confortável para ele. Se isso ocorrer, a prótese final pode ser construída usando-se a temporária como guia de trabalho.

Nos casos em que uma ponte provisória deve ser usada por um largo período de tempo é aconselhável construí-la em laboratório com resina termopolimerizável processada sob pressão. É tomada uma impressão inicial da boca, da forma como ela se apresenta. Este modelo é levado ao laboratório e os dentes são preparados no modelo. Os dentes que serão extraídos são cortados fora do modelo e é feito um enceramento diagnóstico como os modelos já em articulador. Este enceramento é incluído e processado. Este é um splint de laboratório.

O splint é levado à boca na hora em que os dentes săo preparados.

Se ele não se adaptar podemos aliviar o interior das coroas ou preparar mais os dentes. Se ele adaptar sem resistência poderá ser reembasado com resina acrílica autopolimerizável. Geralmente o splint processado não descolore quando usado por mais de 6 meses. Ele é mais resistente e necessita menos reparos porque foi polimerizado sob pressão.

Uma ponte temporária bem construída, com contornos, ameias e oclusão adequados diminui a fase periodontal do tratamento. Na verdade é muito frequente que um bom resultado periodontal não possa ser conseguido sem primeiro construirmos uma ponte temporária adequada. Durante o tratamento ela pode ser removida para obtenção de meIhor visão e acesso.

Após o tratamento periodontal, se as coroas clínicas ficarem muito aumentadas, a ponte provisória pode ser reembasada. Por todos estes fatores a restauração provisória tornase uma parte muito importante em tratamentos protéticos periodontais.
REFERÊNCIAS BIBLIOGRÁFICAS

01. BARGHE, N. \& SIMMONS, E.W. The marginal integrity of the temporany acrylic resin crow. J. Prosth. Dent., St. Louis, v.36, p.274-277, sept. 1976.

02. BROEDEN, M.; CLARKE, R.L.; PEARSON, G.J.; KEYS, W. A new temporary crown and bridge resins. Br. Dent. J. London, v.141, p.269-272, 1976

03. CRISPIN, B.J.; CAPUTO, A.A. Color stability of temporary restorative materials. J. Prosth. Dent. St. Louis, v.42, p.27-33, 1979.

04. CRISPIN, B.J.; WATSON, J.F.; CAPUTO, A.A. The marginal accuracy of treatment restorations. A comparative analysis. J. Prosth. Dent. St. Louis, v.44, n.3, p.283-290, sept. 1980.

05. DONALSON, D. The etiology of gingival recession associated with temporary crowns. J. Periodontol. Chicago, v.45, p.468-471, 1974.

06. DONOVAN, T.E.; HURST, R.G.; CAMPAGNI, W.V. Physical properties of acrylic resin polymerized by four differents techniques. J. Prosth. Dent. St. Louis, v.54, p.522-524, 1985.

07. DYKEMA, R.W.; GOODACRE, C.J.; PHILLIPS, R.W. Practice in fixed prosthodontics, ed.4. Philadelphia: W.B. Saunders Co., 1986. p.77-90.

08. FERRACANE, J.L. Correlation between hardness and degree of conversion during the setting reaction on unfilled dental restorative resins. Dent. Mater. Washington, v.1, p.11-14, 1985.

09. KRAEMER, I.R.H.; McLEAN, J.W. The response of the pulp to self polymerizing acrylic restoration. Part I. Br. Dent. J. London, v.92, p.225-261, 1952.

10. KRAEMER, I.R.H.; MCLEAN, J.W. The response of the human pulp to self polymerizing acrylic restorations. Part II. Br. Dent. J. London, v.92, p.281-287, 1952.

11. KRAEMER, I.R.H.; McLEAN, J.W. The response of the human pulp to self polymerizing acrylic restorations. Part III. Br. Dent. J. London, v.92, p.311-315, 1952.

12. LANDESMAN, H.M.; SPECTOR, M.R. Provisional restorations in clinical dentistry. Boston, John Wright PSG Inc., 1982, p.260,

13. LANGELAND, K.; LANGELAND, L.K. Pulp reactions to crow preparation, impressions, temporary crow fixation and permanent cementation. J. Prosth. Dent. St. Louis, v.15, p.129-143, 1965.

14. McCABE, J.F.; GREFFNER, I. Temporary crown and bridgework. Dent. Update, Guildford, v.7, p.361-373, 1980.

15. RICHARDS, N.D.; MITCHELL, R.J. Effects of materials and techniques on the accuracy of temporary fixed partial dentures. IADR Abstract n.1484. J. Dent. Res. Washington, v.53, p.336, 1984.

16. ROBINSON, F.B.; HOVIGITRA, S. Marginal fit of direct temporary crows. J. Prosth. Dent. St. Louis, v.47, p.390-392, 1982.

17. WAERHAUG, J. Temporary restorations: Advantagens. Dent. Clin. North Am. Philadelphia, v.24, p.305-316, 1980.

18. WANG, R.L. et al. A comparison of resins for fabricating provisional fixed restorations. Int. J. Prosthodontics, v.2, n.2, p.173-184, march/apr. 1989.
R. Fac. Odontol.

Porto Alegre

V. 33

N. 2

p.28-31

DEZEMBRO

1992 